\title{
Evaluation of the Daycare Mangers' Knowledge, Attitude, and Practice on Lead in Drinking Water at Daycares Licensed by the Fraser Health Authority
}

\author{
By \\ Jill (Chang-Jung) Lin \\ Bachelor of Technology, British Columbia Institute of Technology, 2017
}

BRITISH COLUMBIA INSTITUDE OF TECHNOLOGY

April 2017

All rights reserved. This work may not be reproduced in whole or in part, by photocopy or other means, without permission of the author 
The views expressed in this paper are those of the author and do not necessarily reflect the official policy, position or views of British Columbia Institute of Technology, the Environmental Health Program or its faculty. 


\title{
Evaluation of the Daycare Mangers' Knowledge, Attitude, and Practice on Lead in Drinking Water at Daycares Licensed by the Fraser Health Authority
}

\author{
Jill (Chang-Jung) Lin ${ }^{1}$, Helen Heacock ${ }^{2}$, Reza Afshari ${ }^{3}$, Fred Shaw ${ }^{4}$ \\ ${ }^{1}$ Lead Author, B. Tech Student, Student of Health Sciences, British Columbia Institute of Technology, 3700 Willingdon Ave, Burnaby BC V5G 3H2 \\ ${ }^{2}$ Supervisor, School of Health Sciences, British Columbia Institute of Technology, 3700 Willingdon Ave, Burnaby BC V5G 3H2 \\ ${ }^{3}$ Contributor, British Columbia Centre for Disease Control, 655 West $12^{\text {th }}$ Ave., Vancouver, BC V5Z 4R4 \\ ${ }^{4}$ Contributor, School of Health Sciences, British Columbia Institute of Technology, 3700 Willingdon Ave, Burnaby BC V5G 3H2
}

\begin{abstract}
Background: Daycares in $\mathrm{BC}$ fall under the Community Care and Assisted Living Act which require all daycare facilities to provide a safe environment, including drinking water. Young children who have been exposed to lead in drinking water at schools and daycares can incur serious health effects, including damage to cognitive development. Previous research has demonstrated that even low levels of blood lead concentration are associated with intellectual disability, slowed growth and development, lowered ability to concentrate, decreased academic achievement and behavioural problems. Individuals' knowledge, attitude and practice (KAP) on drinking water can influence on how the children consume drinking water and potentially cause adverse health effects. This study evaluated daycare managers' knowledge, attitude, and practice (KAP) on lead in drinking water related to this issue.
\end{abstract}

Method: This study was conducted by collecting 106 responses from a KAP survey to evaluate the knowledge, attitude, and practices regarding drinking water contaminants. The survey was distributed to daycare managers in Fraser Health region. The responses were analyzed with regression and correlation, one-way ANOVA, and chi-square tests.

Results: There was a statistically significant correlation between the age of daycare manger and their knowledge $(\mathrm{t}$-test $=0.0309)$. All other tests showed no statistical correlation, difference, and/or association ( $\mathrm{p}$-value greater than significance level of 0.05 on all parameters) between managerial experiences, age of managers, types of daycares in their knowledge, attitude, and practice regarding lead in drinking water in daycare facilities. The data of KAP questionnaires indicated that most daycare mangers do not fully understand and not are sufficiently educated regarding lead toxicity in drinking water.

Conclusions: The results of KAP surveys showed that an educational intervention by the government or local health authorities is highly recommended and needed to improve the daycare managers' knowledge, attitude, and practice regarding lead in drinking water. Additional research is required to confirm this.

Keywords: Lead, water contaminants, drinking water, daycares, knowledge, attitude, practice, perception 


\section{Introduction}

The BC Ministry of Education mandates all school districts to conduct and report drinking water tests regularly for lead concentration to ensure drinking water quality $(1,2)$ in schools. However, this mandate is only applied to school districts, and not to daycares in BC. Daycares in $\mathrm{BC}$ fall under the Community Care and Assisted Living Act (3) which requires all care facilities to provide a safe environment, including drinking water. Most care facilities are operated in older buildings, and may have used lead service lines for their drinking water. Lead is well-known for its adverse effects on health, but few people realize its existence in drinking water. For this reason, Dr. Reza Afshari, a senior toxicologist who is an overseeing official from the BC Centre for Disease Control (BCCDC), has recommended a research project with the purpose of evaluating daycare managers' knowledge, attitude, and practice (KAP) of this issue. In addition, this study can also determine whether there are any misconceptions in KAP for future educational programs on lead toxicity in drinking water.

Dr. Afshari presented the seriousness of health effects of young children exposed to lead in drinking water at schools and daycares, and stated that lead exposure can lower young children's intelligence quotient (IQ) and cause intellectual disability if their IQ is under 70, which is classified as a disease. This issue not only increases the costs to the health care system, but becomes a burden to one's family and the society. In addition, according to Vancouver Sun report (May 27, 2016) (4), drinking water in $\mathrm{BC}$ schools is not tested annually for lead. However, more than a quarter of BC's school districts have found lead in drinking water exceeding safe limits. Neither the provincial government, school district trustees nor public health officials are taking responsibility with the issue of lead in drinking water. As result, the public could be confused with the testing results and the control measures, such as the frequency of flushing water lines.

The Vancouver Sun (4) mentioned that 92 percent of BC's 1578 public schools have the potential to have lead exposure in their water system due to using old lead pipes or pipes with lead solder built before 1990 that connect the potable water lines. The article stated that experts have suggested flushing the pipes by running the water for several minutes, especially after the period of stagnation, as the solution. However, there is no definite control measures nor prevention for lead exposure in drinking water in schools except completely replacing the lead pipes or pipes with lead solder.

Current literature has highlighted many adverse effects of lead on young children's health and has analyzed the control and preventative measures of lead exposure in drinking water at daycares and schools. The literature review identified research, policy, and knowledge gaps, which are important to identify as the public becomes more aware of the health impacts of lead on their children.

\section{Literature Review}

\section{Lead exposure and Blood lead level (BLL) in children}

According to the Center for Disease Control and Prevention (CDC) (5), lead can be exposed through lead-based paints, dust and water. There is no safe BLL in children under the age of 6 that has been established. Young children, infants and pregnant women are the most vulnerable groups to the health effects of lead exposure. Since children have relatively smaller body sizes than adults, the elevation of BLL will have significant health effects on them. A study conducted by Ngueta et al. (6) stated that children can absorb $40-50 \%$ of water-soluble lead by ingestion. A long-term exposure of lead in tap water could result in increased BLL in children and eventually reach the established action levels (10-15 ug/L). Also, an increase of 1 $\mathrm{ug} / \mathrm{L}$ lead in water would result in 35\% BLL after 150 days of exposure. This indicates that even if water lead concentration is measured below the current drinking water guidelines in Canada and United States, a long-term exposure of lead may still impact the young children's health (6). 
In the chemical parameters of Guidelines for Canadian Drinking Water Quality (GCDWQ) (7), the maximum acceptable concentration (MAC) of lead is $0.010 \mathrm{mg} / \mathrm{L}$ or $10 \mathrm{ppb}$. Lead can be usually found in some metal water taps, water pipes, or pipes connectors from the house to the main water system in the street. Due to the corrosion of older fixtures or connection of the pipes, lead gradually leaches into the water supply (8). Levin et al. (9) mentioned that lead pipes are commonly found in older homes, but even in new homes, the legally "lead-free" plumbing can contain up to $8 \%$ lead which leaches more easily than older fixtures.

However, since lead sampling in drinking water is difficult and uncommon, exposure to lead from drinking water is usually underestimated.

A study by Deshommes et al (10) stated that lead testing was carried out in four Canadian provinces from elementary schools, daycares, and other large buildings. The authors found that the maximum concentrations reached 13,200 and $3890 \mathrm{ug} / \mathrm{L}$ in long and short stagnations periods respectively, which were considerably over the MAC lead level. In addition, lead levels in school drinking water was found to be higher than the residential drinking water due to stagnation including overnight, weekends, and vacation with heavy consumption after these times (9). Another study by Shell (11) conducted in Flint, Michigan uncovered that the water from the Flint River corroded the city water pipes and leached lead into their water system. This resulted in an increase of BLL in children at or above $70 \mathrm{ug} / \mathrm{L}$ from $2.4 \%$ to $4.9 \%$ between 2013 and 2015 (11). Overall, these studies demonstrated that the corrosion of water pipes causing lead to leach into the water system are the main sources for lead exposure in water.

\section{Impact of lead exposure}

According to CDC (12), "Childhood lead poisoning data, statistics, and surveillance' states that there is no identified safe BLL to children age less than 72 months. These children who are exposed to lead in their surroundings are at risk for damage to the brain and nervous system, delayed growth and development, experiencing difficulties in hearing and speech, and causing learning and behavioural problems, especially in reducing IQ, Attention deficit hyperactivity disorder (ADHD), juvenile delinquency, and criminal behaviour. Health Canada (7) also states that lead has both biochemical and neurobehavioural effects for intellectual development behaviour in infants and young children under 6 years. Furthermore, lead can lead to anemia and central nervous system damage.

CDC (5) states that even low BLL can affect IQ, concentration, and academic achievement. The adverse effects can also lead to renal dysfunction (6). These adverse effects cannot be reversed or corrected in any treatment. The health effects can occur at BLL below $100 \mathrm{ug} / \mathrm{L}$, which is the current federal provincial-territorial intervention level. A BLL of $50 \mathrm{ug} / \mathrm{L}$ is set as a threshold for threats of harm in children. This low level lead exposure has been found to have an association with cognitive deficits (11). Hornung et al. (13) indicated that lead exposures at school age (5-6 years old) have more damage to IQ or neuroanatomical deficits than for children at age 2, and result in learning or behavioural problems while undergoing cognitive and behavioural development.

\section{Knowledge, Attitude and Practice}

A relevant KAP study was done by Marina Bebek (27) who conducted a knowledge assessment differences between daycare staff and parents on lead sources and its health effects on children. Based on the study, there was no significant differences in knowledge levels between the two groups, and both groups showed significant gaps in knowledge on lead information and preventive measures. Even though both groups' education levels were some college or more, their results showed a significant lack of knowledge on lead exposure and preventative measures, with an average test score of $34.2 \%$. It is important to identify the knowledge gaps in both groups who are the most associated with the young children to target health promotion projects and additional education and training on the lead exposure. 
In addition, operators' knowledge of lead exposure and attitude toward the drinking water contaminants may or may not have direct linkage to their drinking water practice in a daycare facility. By identifying the knowledge gaps and increasing the awareness of lead exposure, the operators' drinking water practice may be likely to change and improve to lower the risk of lead exposure in young children.

\section{Elimination}

There are ways to eliminate lead exposure in drinking water and day-to-day water usage. According to CDC (8), if water has been stagnated for more than 6 hours, one should keep the tap water on cold running for 5 minutes before using, with additional flushing times before consumption, and with additional 1-2 minutes before cooking. Hot water or boiled water should be avoided from consuming since it tends to contain higher lead concentrations than cold tap water. In addition, one can consume bottled water or obtain a certified water filtration system to reduce or eliminate lead exposure. Individuals can also try to replace all the lead solder to copper pipes in their houses. Since human skin does not absorb lead in water, it is safe for both adults and children to shower or bath with slightly elevated amounts of lead in water (8).

\section{Control measures}

Since individuals cannot see, smell or taste lead in drinking water, the only way to identify the lead contamination would be by lead water testing. Individuals should contact their local health authority for testing information, especially after plumbing construction in older buildings or housing, or test themselves (8). However, the health authorities will not test private homes on Metro Vancouver provided water. Since public water lead sampling does not usually include schools and daycares, the local health agency should have closely monitored water supplies and mandatory corrective actions in schools and daycare facilities (14). In addition, the lead water tests should be conducted more than once and from different water sources since lead levels vary in any fountain or tap (15). An interesting study conducted by Miranda et al. (16) suggested that the chloramines used as a disinfectant in drinking water may lead to an increase in BLL by causing corrosion of pipes. Hence, changing or adjusting the disinfectant for water treatment could minimize the lead level in water.

\section{Prevention}

Adverse effects of lead are irreversible in any treatment; hence, it is important to apply lead exposed preventative measures. According to CDC (5), only use cold water from the tap for drinking, cooking and making baby formula, since hot water tends to absorb and concentrates more lead from the plumbing in the user's house. Coles et al. (17) also suggested that the manufacturers of plumbing materials should avoid any lead components and examine the pipes and fixtures for the leach of lead into water. In addition, the public should be educated on the exposure and health impacts of lead, which may drive consumers to buy lead-free pipes and minimize the lead-pipes markets. Furthermore, the auditing of the plumbing and plumbing materials companies should be conducted regularly as requirements of manufacturers' goals. And, the government should offer monetary incentives for purchasing and replacing the lead pipes. Children living in lead present drinking water areas should also have their BBL tested on regular basis in schools and daycares (17).

The health effects of lead exposure can also be linked to social inequality, nutrition and education. Children who are living in a low socioeconomic status are more susceptible to lead than others due to nutritional deficiencies in iron, calcium or zinc encouraging lead absorption (11). It is potentially that the lowlevel lead exposure can be mitigated by improving surroundings with education to parents and children and improved nutrition.

\section{Conclusion}

Although there are GCDWQ for the MAC of lead level and many studies related to the health impacts on lead exposure among young children 
in residential areas, schools, or daycares, there is not much improvement or action being done to eliminate lead exposure in drinking water systems. The purpose of this research project was to examine whether the daycare managers understand the health impact on children by drinking lead water at daycares licensed by the Fraser Health Authority. The study also determined if there should be corrective actions undertaken by the health authority and the government to eliminate lead exposure to young children via drinking water.

\section{Methods}

The purpose of this study was to evaluate the Knowledge, Attitude, and Practice (KAP) of daycare managers regarding how the presence of lead in pipes affects drinking water (DW) in daycare facilities licensed by Fraser Health (FH) Authority. Analysis of the survey involved comparing the KAP responses to managerial experience, age of the respondent, and the types of daycare worked in.

The equipment and materials used for this study included: a computer with Internet access, lists of daycares licensed by FH Authority $(18,19,20)$, statistical analysis programs (NCSS 11 (24), SPSS (25) and MS Excel 2010 (26)), a word processing program (MS Word 2010 (22)), an online KAP survey with a cover letter and a consent form (23) via email and Google Forms (21), a script, and a cellphone for contacting daycare managers.

The data collection was performed by distributing KAP online surveys to daycare managers via email and/or directly to $\mathrm{FH}$ licensing officers. The purpose of using KAP surveys was to evaluate the efficacy of current DW intervention programs and to determine possible misconceptions in KAP for future educational programs in DW knowledge and practice. The style of the survey was recommended by Dr. Reza Afshari, a senior toxicologist from BCCDC (personal communication, January 11, 2017). The KAP study was also recommended by Ms. Marina Bebek who conducted a study on assessing knowledge differences between daycare staff and parents on lead sources (27).

A self-administered online survey distributed via email for Google Forms access was used for data collection. The participants of the study were selected non-randomly. Initially, the list of daycare facilities licensed by the FH Authority was provided by BCCDC and the FH regional licensing manager, Ms. Annette Dellinger. Due to a low response rate, additional daycare facilities were selected from the online list of child care facilities licensed by the FH authority $(18,19,20)$.

Data collected by Google Forms were transferred into Excel spreadsheets, which were further analyzed by NCSS 11 and SPSS. Data was divided based on the demographic information of daycare managers and the KAP questions they answered.

\section{Inclusion and Exclusion}

The contacted daycares were current operating facilities, serving children under age 5 , and licensed by FH. Only the daycare managers were permitted to complete the KAP questionnaires. Facilities looking after children under five years of age were targeted because these children are most vulnerable to water contaminants, especially lead (6). As this study was initiated by the $\mathrm{FH}$ regional licensing manager, Ms. Dellinger, as well Dr. Afshari from BCCDC, only facilities in FH were selected for this study. Since there was only an English version of the survey, knowledge of the English language was required.

\section{Results}

\section{Data Description}

The collected data of the survey was a combination of numerical and nominal data (28). The questions for knowledge and practice were scored based on the correct answers and level of relevance. For knowledge, a score of 12/14 and above was considered "high", a score between 9$12 / 14$ was considered "medium", and a score of 
8/14 and below was considered "low". For practice, a score of $9 / 12$ and above was considered "high", a score between 4-8/12 was considered "medium", and a score of $3 / 12$ and below was considered "low". The attitude section was assessed for each water contaminants as either "Good, Bad, Neither, and Not Sure". The grading scheme of knowledge and practice and attitude assessment were conducted similarly to the KAP evaluation on Seafood Contaminants by Matthew Loo (29).

In total, there were 106 responses from the managers, and data were compiled onto MS Excel spreadsheets and further analyzed by NCSS and SPSS. Three types of statistical tests were applied to evaluate the KAP based on managerial experience, the age of managers and type of daycare. Regression and Correlation and One-Way ANOVA were used to analyze Knowledge and Practice, and Chi-Square test was used to analyze Attitude (30).

\section{Descriptive Statistics}

There were 106 responses in total. The gender distribution for the managers was $97.2 \%$ female and $2.8 \%$ male. The mean (SD, minmax) of the age of managers was 47 years (10.25, 28-72 years old), and managerial experience was 11 years $(7.60,0.083-37$ years). The highest level of education completed by the managers was $59.4 \%$ with a certificate or diploma, $13.2 \%$ with an undergraduate degree, $10.4 \%$ with a graduate degree or higher, $9.4 \%$ with some post-secondary, $3.8 \%$ with high school or less, and $3.8 \%$ with others. The type of daycares were $70.8 \%$ private, $16 \%$ public and $13.2 \%$ others. The majority of fixtures used in daycare facilities were $84 \%$ from taps, $22.6 \%$ from bottled water and $4.7 \%$ from fountains. The majority of DW source came from the city water $(\mathrm{n}=106,88.7 \%)$. Only $70.8 \%$ of facilities let the DW run before consumption. The majority of managers run the DW every time before it is consumed ( $n=106,66.2 \%)$ (Figure 1). The mean (SD, min-max) of the length of DW running was 36 seconds (57, 0-240 seconds) (Figure 2). The mean (SD, min-max) of the age of building was 30 years old (16.55, 1-75 years) with $16 \%$ having the pipes repaired recently.
Figure 1: Frequency of number times per day let the drinking water run before consuming. (Note: 0 - None; 1 - Every time it's consumed; 2 Every break; 3 - once; 4 - twice; 5 - Three or more; 6 - Not sure).

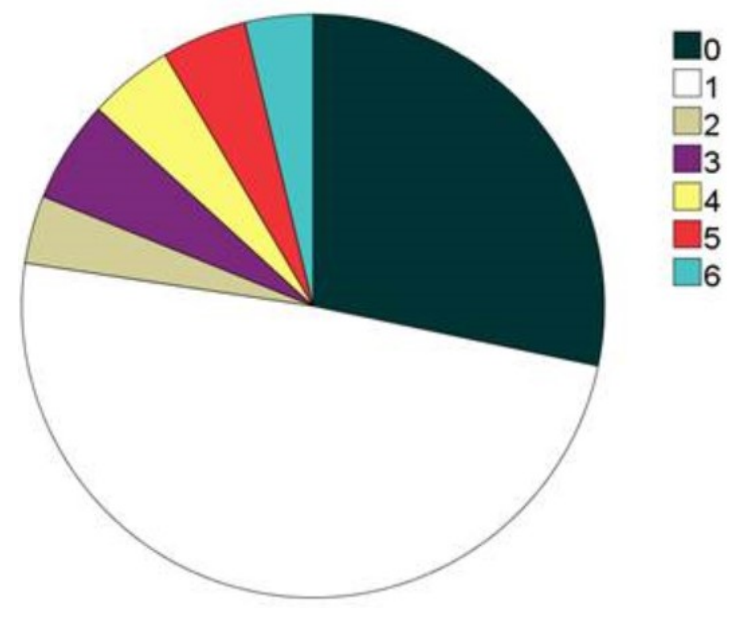

Figure 2: Length of drinking water running before consuming (seconds).

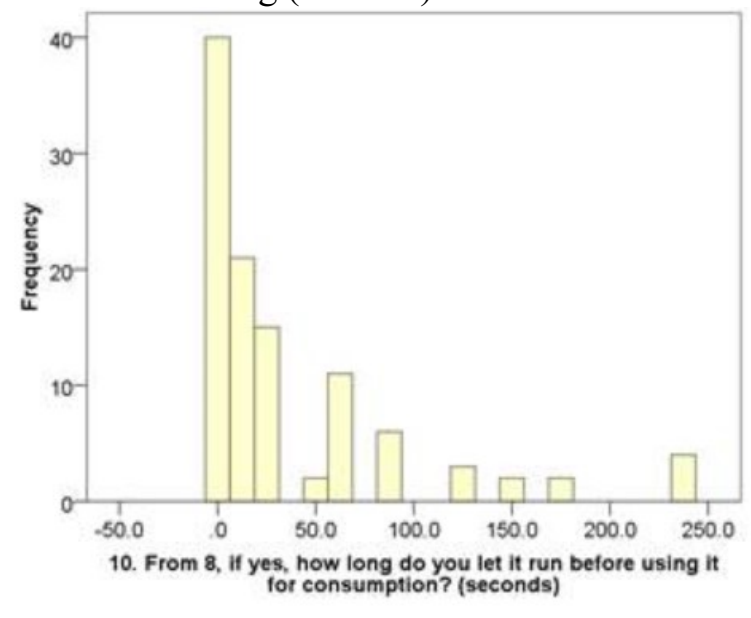

Among the managers, $85.5 \%$ had heard of DW quality, but only $2.8 \%$ received training regarding the regulation of $\mathrm{DW}, 6.6 \%$ received education relating to DW quality, and only $5.7 \%$ believed that boiling DW before consuming increases lead concentration in DW. Also, only 1 person $(0.9 \%)$ allocated some time to train children for potential lead toxicity in DW. The managers believed that most water contaminants can be found in DW (80\% lead, 61\% copper, $47 \%$ E. coli, 36\% Coliforms, 16\% Cadmium, 23 $\%$ Arsenic, $29 \%$ viruses, and $46 \%$ mercury). Over $50 \%$ of the managers believed that the presence of water contaminants in DW is "bad". 
The managers receive information on lead toxicity in DW from the following sources (Table 1): $43 \%$ from the media, $37 \%$ from the internet, but only $24 \%$ from the health authority (top 3 sources). Only 4\% facilities had been tested for lead in their DW. The majority of the children drink their water by filling their water bottles from the taps or fountains $(57.5 \%)$, bringing their own water from home $(50.9 \%)$, and directly taking from taps or fountains (26.4\%). There were $63.2 \%$ using a water filter in their facilities with mostly Brita filtration system (31).

Table 1: P-values for lead toxicity information received from each sources.

\begin{tabular}{|l|l|}
\hline $\begin{array}{l}\text { Information received from the } \\
\text { following sources about the } \\
\text { impact of lead toxicity in drinking } \\
\text { water. }\end{array}$ \\
\hline Sources & p-value \\
\hline $\begin{array}{l}\text { Media (TV, social } \\
\text { media, newspaper) }\end{array}$ & $\mathbf{0 . 0 0 9}$ \\
\hline Internet & $\mathbf{0 . 0 1 0}$ \\
\hline Health Authority & 0.939 \\
\hline Parents & 0.665 \\
\hline Teachers & 0.946 \\
\hline Pamphlets/Brochures & $\mathbf{0 . 0 2 3}$ \\
\hline
\end{tabular}

Regarding the types of disease associated with poor water quality, the managers considered $46 \%$ with gastrointestinal (GI) illness, $10 \%$ with lead poisoning, and $11 \%$ with infectious disease. Regarding the symptoms related to lead toxicity, the managers considered $25.5 \%$ GI illness syndrome, $13.2 \%$ with development delay, $9.4 \%$ with a feeling of fatigue, $9.4 \%$ of the neurological syndrome, $7.5 \%$ with irritabilities on mucous membranes, $5.7 \%$ with weight loss and $4.7 \%$ with fever or flu-like syndrome. Regarding any comments for their DW, $50 \%$ of managers replied "none" to this question, $13 \%$ of managers considered "BC has the best DW or safe to drink", $7 \%$ of managers felt concerned now after completing this survey, and $6 \%$ of managers felt more information on DW quality and testing was needed in daycare facilities. Furthermore, the mean (SD, min-max) of knowledge score for the managers was $5(3.04,0-12)$ (Figure 3$)$. The mean (SD, min-max) of practice score for the managers 3.5 (2.45, 0-9) (Figure 4).

Figure 3: Distribution of knowledge scores for daycare managers.

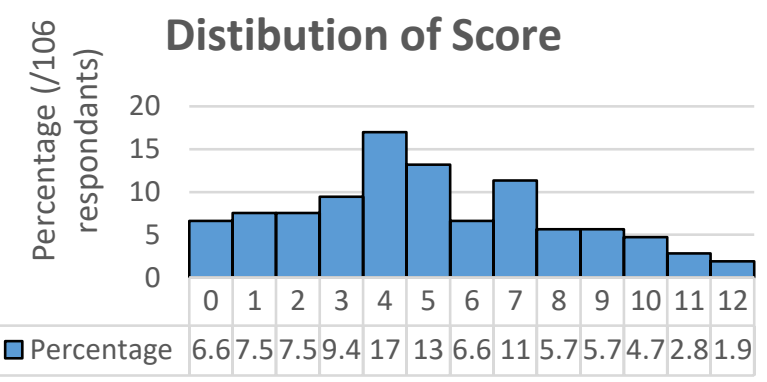

Knowledge Score

Figure 4: Distribution of practice scores for daycare managers.

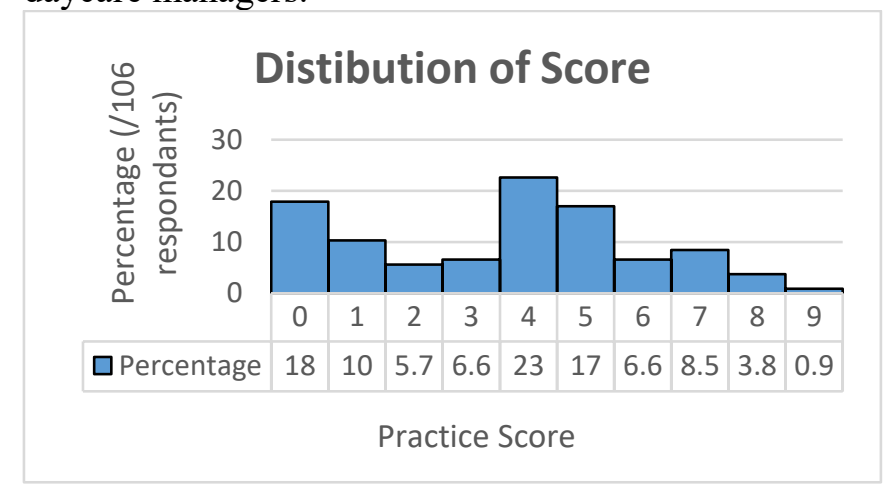

\section{Inferential Statistics}

Regression and Correlation tests were used for knowledge and practices analysis. Firstly, the Correlation coefficient ( $r$ ) of managerial experience (Exp) and knowledge was 0.1421. Since " $r$ " was between 0 and $+/-0.25$, there was little or no relationship between managerial experience and knowledge. The significance level of $t$-test was $r=0.1461$; hence, the Ho was not rejected. Secondly, the significance level of a t-test of manager's age (age) and knowledge was 0.0309 . Therefore, so the Ho was rejected. However, $r=0.2097$ which indicated little or no relationship between the age and knowledge. In other words, the ability of the regression line to predict age and knowledge was very weak. As for practice, the " $r$ " of Exp and practice was 0.0017 showed little or no relationship between Exp and practice. The significant level of this t- 
test was 0.9860 ; therefore, Ho was not rejected. Fourthly, the "r" of the age and practice was 0.0379 again, little or no relationship between the age and practice. The Ho was not rejected since the significant level of this t-test was 0.6995. Lastly, the " $r$ " of knowledge and practice was 0.1121 suggesting little or no relationship between knowledge and practice. The significance level of the t-test was 0.2527 ; hence, Ho was not rejected.

Another test, One-Way ANOVA was conducted for types of daycares (public, private and others) in knowledge and practice. For knowledge, the variable was not normality distributed. Therefore, the Kruskal-Wallis oneway ANOVA on Ranks was performed. "Not Corrected for Ties" was chosen for the test results due to different means for three types of daycare $($ public $=48.15$, private $=52.37$, other $=$ 67.12). The probability level $=0.20515$, therefore, Ho was not rejected. As for practice, the variable failed to meet normality, so Kruskal-Wallis one-way ANOVA on Ranks was performed. "Not Corrected for Ties" was chosen for the test results for the three means (public $=$ 56.65 , private $=54.81$, other $=41.73$ ). The probability level $=0.32937$, did not reject Ho.

Chi-square tests were used to analyze data managers' attitude towards water contaminants. The subjects were grouped based on their managerial experiences and their age. Pearson's Chi-Square was performed for both groups. Since all the p-values of contaminants for both groups exceeded 0.05 , the results concluded that there was no statistically significant association between managers' attitude towards water contaminants either grouped by managerial experiences or by age.

Furthermore, additional tests were performed with SPSS software. There was no association between the age and knowledge score. Yet, for the highest education levels of the managers, obtaining a graduate degree or higher produced significantly higher knowledge scores than having certificate or diploma $(\mathrm{p}=0.045)$ and an undergraduate degree $(\mathrm{p}=0.025)$. Managers' age was also associated with receiving information from the various sources regarding on the impact of lead toxicity in drinking water. Information received from the media, internet, and pamphlets/brochures were significantly higher than other sources in all the respondents. In addition, there was no significant difference between the age and questions regarding training of DW regulation received $(p=0.148)$, daycare tested for lead $(p>0.05)$, water quality education received $(\mathrm{p}=0.946)$, and DW source $(\mathrm{p}=0.456)$.

Table 2: P-values for attitude towards each component in years of managerial experience. There is no association in attitude and years of managerial experience.

\begin{tabular}{|l|l|}
\hline Components & P-value \\
\hline Coliforms & 0.69 \\
\hline E.coli & 0.27 \\
\hline Virus & 0.32 \\
\hline Lead & 0.78 \\
\hline Mercury & 0.61 \\
\hline Arsenic & 0.36 \\
\hline Copper & 0.44 \\
\hline Cadmium & 0.79 \\
\hline
\end{tabular}

Table 3: P-values for attitude towards each component in age of daycare manger. There is no association in attitude and age of daycare manager.

\begin{tabular}{|l|l|}
\hline Components & P-value \\
\hline Coliforms & 0.26 \\
\hline E.coli & 0.62 \\
\hline Virus & 0.29 \\
\hline Lead & 0.39 \\
\hline Mercury & 0.42 \\
\hline Arsenic & 0.07 \\
\hline Copper & 0.53 \\
\hline Cadmium & 0.56 \\
\hline
\end{tabular}

There was potential for Type I (Alpha) and Type II (Beta) errors in the study. All the tests were susceptible to Type-II or a beta errors. Therefore, increasing the sample size for the tests for future studies may be sufficient to remedy the error (28). As for the type-I or alpha error, there was a potential but weak possibility for this error to occur since most Hos for the tests were not rejected. However, those three Hos that were rejected all had p-values between 0.01-0.05 which may suggest alpha errors and 
may be really no difference (28). However, due to limit time and resources, the Beta error was seemed to be the major one to be discussed when fail to reject Ho. Furthermore, the collected data may be a weak representative for all daycares licensed by FH (1691 daycares in total) that only 106 responses were valid to be analyzed.

\section{Discussion}

The purpose of the study was to determine the overall knowledge, attitude and practice level of daycare managers in Fraser Health region regarding lead in drinking water (DW). The rationale for this study was that there was a potential lack of awareness or information regarding the risks of lead in DW in Fraser Health regions. Based on the results of the study, the average knowledge score was 5/14 (36\%) and average practice score was 3.5/12 (29\%) for the daycare managers. Applying the grading scheme similar to Matthew Loo's KAP assessment (29), knowledge on lead in DW and DW contaminants was considered "low", and the practice levels was "Medium-low". Both scores indicate there was a need for intervention in the education of daycare's managers, especially in their DW knowledge.

Their attitude results (Table 4) showed that over than half of the managers perceived DW contaminants correctly. Attitudes toward coliforms might be a bit confusing to the managers. This may be due to not all coliforms being harmful to humans, and many coliforms being essential in nature and for humans (32). Nearly all respondents agreed that E.coli, viruses, lead, mercury and arsenic are harmful to human health when found in their DW. Since copper has been commonly used as the material for pipes, some people were not sure the effect of copper in DW. Because most people are not familiar with the environmental and health effects of cadmium, nearly half of the managers stated "not sure" attitude towards it. While doing a few surveys via telephone with the managers, most believed that any presence of metal in DW is all "Bad".
According to Guidelines for Canadian Drinking Water Quality (GCDWQ) (7), water contaminants can cause harm to the public or act as indicators for water contamination.

Coliforms, usually referred to Total coliforms, are used as a tool to monitor the DW treatment system. E. coli is an indicator for any fecal contamination in DW and can cause gastrointestinal illness (GI). Viruses are commonly associated with GI upset, respiratory systems, central nervous system (CNS) infection, and other complications. Based on GCDWQ, lead, mercury, arsenic and cadmium all can pose negative effects on human health when exceeding the maximum acceptable concentrations (MAC). Mercury can cause irreversible neurological symptoms; arsenic is classified as a human carcinogen, and cause skin, vascular and neurological effects; cadmium can cause kidney damage and softening of bone. Copper, on the other hand, is more an aesthetic objective on taste. It is essential in human metabolism, and its adverse health effects occur at much higher levels than the aesthetic objective.

As for lead, which is the main element for this study, it causes many adverse health effects even at a level lower than the MAC from GCDWQ. Lead in DW is mainly from lead service lines or soldering entering the building. It can cause biochemical and neuro-behavioural effects - intellectual and behaviour development- especially in infants and young children (under 6 years). In addition, lead is especially concerning associated with anemia in unborn child and CNS effects resulting in altered intellectual development, behaviour, size and hearing in infants and young children under 6 years. Lead is classified as probably carcinogenic to humans. According to CDC (5) and Ngueta et al. (6), there is no safe blood lead level in young children, and a long-term exposure of low-level lead can still impact irreversible neuro-behavioural effects on the young.

In the results of inferential statistics, the managerial experience was not correlated with the managers' DW knowledge and practice, and not associated with their attitude towards water 
Table 4: Summary of managers' attitudes toward drinking water components.

\begin{tabular}{|c|c|c|c|c|}
\hline Components & Good & Neither & Bad & Not sure \\
\hline Coliforms & $1.89 \%$ & $6.60 \%$ & $53.77 \%$ & $37.74 \%$ \\
\hline E.coli & $0.94 \%$ & $1.89 \%$ & $88.68 \%$ & $8.49 \%$ \\
\hline Virus & $0.94 \%$ & $2.83 \%$ & $86.79 \%$ & $9.43 \%$ \\
\hline Lead & $0.94 \%$ & $2.83 \%$ & $89.62 \%$ & $6.60 \%$ \\
\hline Mercury & $0.94 \%$ & $4.72 \%$ & $83.02 \%$ & $11.32 \%$ \\
\hline Arsenic & $0.94 \%$ & $2.83 \%$ & $80.19 \%$ & $16.04 \%$ \\
\hline Copper & $1.89 \%$ & $6.60 \%$ & $67.92 \%$ & $23.58 \%$ \\
\hline Cadmium & $0.94 \%$ & $4.72 \%$ & $50.94 \%$ & $43.40 \%$ \\
\hline
\end{tabular}

contaminants. Hence, more experience in being a daycare manager did not mean obtaining the most up-to-date or accurate DW knowledge. In addition, the knowledge scores achieved by the managers showed no statistical correlation with their DW practice in daycare. Age of managers, on the other hand, did show statistically significant correlation with managers' DW knowledge. However, since the correlation $(\mathrm{r}=$ 0.2097 ) was between 0 to $+/-0.25$, the ability of the regression line for age and knowledge prediction was very weak. Hence, even though the test showed older daycare managers scored higher, the correlation was too weak to infer that age is positively correlated with knowledge.

Also, there was no association between attitude towards DW contaminant and age. From Table 2, most managers viewed any metal or microbes present in DW as deleterious for DW, especially in daycare facilities. Similar to managers' attitude, the older manager did not reflect better DW practice. Furthermore, there was no difference in DW knowledge and practice between the types of daycare - public, private and others. None were better or worse than the other considering children's DW intake in daycare facilities. These findings were similar to the study conducted by Ms. Marina Bebek (27), who also found that there was no significant difference in lead knowledge scores between the parents and Early Childhood Educators (ECEs) in Burnaby and Surrey, BC.

In addition, almost none the managers had heard of DW quality nor had proper training in DW regulation and education. Only 5.7\% of managers had correct perception that boiling
DW can worsen and increase lead concentration. Only 1 out of 106 daycare spent the time to educate children about potential lead toxicity presence in DW. Clearly, there is insufficient DW education and information being transferred by daycare managers surveyed in the Fraser Health Authority. Surprisingly, 63.2\% of operators who used Brita filtration systems for their drinking water on site, believed it improved the taste and safety of DW.

Brita filter contains activated carbon to reduce chlorine and ion exchange resin to reduce metals - copper, cadmium, mercury and zinc. Through the Brita faucet filter, the sediment and particulates in the water are trapped by a nonwoven screen, and then a compressed block of carbon and zeolite reduces chlorine taste and odour and lead (37). Brita faucet filtration system (point-of-use type) is certified by National Sanitation Foundation (NSF) and the Water Quality Association (WQA) in NSF/ANSI Standards 42 (aesthetic effects) and 53 (health effects) $(35 ; 36 ; 37)$. Brita bottles are NSF/ANSI 42 (aesthetic effects) certified to reduce chlorine taste and odour and nominal particulates (34). Hence, only the Brita faucet filtration systems are certified in contaminants and lead reduction. Others, including Brita water bottles, pitchers and dispensers, are mostly for aesthetic effects, even though their websites have listed reduced metal contaminants and particulates from using their products (38).

Vancouver Coastal Health (VCH) authority implements a "protecting children from lead in DW at child daycare facilities" program which requires the child daycare operator to ensure 
their DW safety from lead by meeting the GCDWQ standards (33). Even though most DW supply systems in BC have very low levels of lead, the soft and slightly acidic BC drinking water may dissolve lead from the plumbing fixtures or fittings or lead-containing solder. It is difficult to predict which daycare facilities require flushing, but flushing can help the lead levels return to safe levels below the lead MAC of GCDWQ. VCH asks the operator to develop a plan for their DW based on GCDWQ standards and conduct baseline water quality tests samples. In contrast, there are no lead reduction requirements in the DW program developed especially for the daycare facilities in Fraser Health. Most the managers received lead toxicity information via media and the internet. Only $24 \%$ of the information came from the health authority. In conclusion, there is a definite need for the Fraser Health authority to implement lead in DW programs and to educate or re-educate the managers in daycare facilities, despite their managerial experience, age, or types of daycare they work in.

\section{Recommendations}

Based on the limitations of this study, it is recommended to increase the sample size by having more time to collect the data and to ask the licensing officers to deliver the emails at the beginning of the research period. Also, having a demographic question or applying stratified sampling for the city or areas of daycares would identify which areas of Fraser Health require more attention or where risk assessments regarding lead should be conducted. Furthermore, additional language versions for this survey may be beneficial for the managers to fully understand the questions asked in the survey.

\section{Limitations}

The main limitation of this study was the small sample size. Only 106 daycares participated this study, compared to 1691 daycares in all Fraser Health regions. The sample size was too small to represent the overall daycares. Since the KAP survey was self-administered and completed by the managers in their free time, the managers may have looked up the answers or asked for assistance for completion, which possibly reduced the internal validity of this study.

Another limitation might be that since the KAP survey of this study was conducted online via Google Form, it was impossible to identify the response rate from different Fraser Health regions - Fraser East, Fraser North, and Fraser South. Some areas may participate in the study more than the other areas, and the survey may not be equally distributed to all the daycares within the limited time frame.

Another limitation would be the short time frame for survey distribution. There were only three weeks for the operators to respond to the survey due to the limited research time. After the survey cut-off time, some operators who were interested in this study could not participate. This was also related to the small sample size limitation. In addition, daycare managers are very busy and may not have had the necessary time to complete the survey.

Lastly, language barriers may be a limitation. The survey was only published English, so operators with limited English may not have been able to complete the survey. Some managers would contact the investigator for clarification, but most participants completed the survey without asking the investigator for assistance.

\section{Knowledge Translation}

To improve the knowledge, attitude, and practice towards lead in DW or DW in general, Fraser Health authority could implement lead in DW program or additional education or water sampling requirement, similar to $\mathrm{VCH}$. Also, the childcare licensing officers may require the operators to attend DW courses before issuing or renewing their permits. Based on the results, clearly, there was not much information exchanged or delivered between health authority and the managers. Hence, Fraser Health 
authority should try to look for means, such as the internet or social media, to distribute the information and increase the awareness of lead in drinking water. In addition, since lead can cause adverse effects even at very low levels in prolong periods, especially to children under age 5, the MAC of lead in GCDQW should be set at the lower limit (currently is 10ppm).

\section{Future Research}

Followings are the projects that can be conducted in the future:

1. Another KAP study can be conducted to evaluate the daycare managers/operators DW perceptions before and after DW education or information delivered.

2. Conduct KAP study based on the cities or areas of Fraser Health.

3. Comparison the KAP study between Vancouver Coastal Health and Fraser Health, or other health authorities whether the DW program or education have been implemented.

\section{Conclusions}

The results of KAP survey indicated that most respondents had a low level of knowledge and practice regarding lead in DW despite their years of managerial experience or their age. The types of daycares had no difference in knowledge and practice of lead in DW. And, there was no correlation between knowledge and practice scores of daycare managers. The attitudes towards the drinking water contaminants had no association in their years of managerial experience and age. Overall, depending on the lead analysis of drinking water samples, young children may be potentially at risk of lead exposure due to lack of knowledge and improper practice of managers.

\section{Acknowledgements}

The author would like to thank Helen Heacock for providing support and guidance throughout this study, Reza Afshari for providing recommendation and expertise on this subject and materials, Fred Shaw for supporting this research, and Annette Dellinger for delivering the emails and assistance.

\author{
Abbreviation \\ ADHD - Attention deficit hyperactivity disorder \\ "age" - Age of the managers \\ ANSI - American National Standards Institute \\ $\mathrm{BC}$ - British Columbia \\ BCCDC - BC Centre for Disease Control \\ BLL - Blood lead level \\ CDC - Center for Disease Control and \\ Prevention \\ CNS - Central nervous system \\ DW - Drinking water \\ ECEs - Early childhood educators \\ Exp - Managerial experience \\ FH - Fraser Health \\ FHA - Fraser Health Authority \\ GCDWQ - Guidelines for Drinking Water \\ Quality \\ GI - Gastrointestinal illness \\ IQ - Intelligence quotient \\ KAP - Knowledge, attitude, and practice \\ MAC - Maximum acceptable concentration \\ Min - Minimum \\ Max - Maximum \\ NSF - National Sanitation Foundation \\ " $r$ " - Correlation coefficient \\ SD - Standard deviation \\ VCH - Vancouver Coastal Health \\ WQA - Water Quality Association
}

\section{Competing Interest}

The authors declare that they have no competing interests. 


\section{References}

1. Testing Lead Content in Drinking Water of School Facilities [Internet]. Government of British Columbia: Legislation \& Policy - Public School Policies; [updated 2016 Sept 26] [cited 2016 Oct 21]. Available from: http://www2.gov.bc.ca/gov/content/educationtraining/administration/legislation-policy/publicschools/testing-lead-content-in-drinking-water

2. Drinking Water Protection Regulation [Internet]. BC Laws: Drinking Water Protection Act; [updated 2005 Dec 09] [cited 2016 Oct 21]. Available from:

http://www.bclaws.ca/civix/document/id/loo72/1 oo72/200_2003

3. Community Care and Assisted Living Act [SBC 2002] CHAPTER 75 [Internet]. BC Laws; [updated 2010 Oct 27] [cited 2016 Oct 21]. Available from:

http://www.bclaws.ca/civix/document/id/consol2 1/consol21/00_02075_01

4. Shaw R, Sherlock T. Drinking water in B.C. schools to be tested annually for lead [Internet]. Vancouver Sun: Local News; [updated 2016 May 27] [cited 2016 Oct 21]. Available from: http://vancouversun.com/news/local-news/aslead-found-in-school-water-across-b-c-provincemoves-to-annual-testing

5. Lead - Prevention Tips [Internet]. Centers for Disease Control and Prevention (CDC); [updated 2014 Jun 19] [cited 2016 Oct 21]. Available from:

http://www.cdc.gov/nceh/lead/tips.htm

6. Ngueta G, Abdous B, Tardif R, St-Laurent J, Levallois P. Use of a Cumulative Exposure Index to Estimate the Impact of Tap Water Lead Concentration on Blood Lead Levels in 1- to 5Year-Old Children (Montréal, Canada). ehp. 2016 Mar; 124(3):388-395. Available from: https://ehp.niehs.nih.gov/1409144/\#tab1

7. Guidelines for Canadian Drinking Water Quality - Summary Table [Internet]. Health Canada: Environmental and Workplace Health; [updated 2017 Feb] [cited 2017 Mar 21].
Available from: http://www.hc-sc.gc.ca/ewhsemt/pubs/water-eau/sum_guideres_recom/index-eng.php

8. Water [Internet]. Centers for Disease Control and Prevention (CDC): Lead; [updated 2016 Feb 18] [cited 2016 Oct 21]. Available from:

http://www.cdc.gov/nceh/lead/tips/water.htm

9. Levin R, Brown M, Kashtock M, Jacobs D, Whelan E, Sinks T, et al. Lead Exposures in U.S. Children, 2008: Implications for Prevention. ehp. 2008 Oct; 116(10):1285-1293. Available from: https://ehp.niehs.nih.gov/11241/

10. Deshommes E, Andrews R, Gagnon G, McCluskey T, Mcllwain B, Prévost M, et al. Evaluation of exposure to lead from drinking water in large buildings. Water Res. 2016 Aug 01; 99:46-55. Available from: https://www.ncbi.nlm.nih.gov/pubmed/2713219 8

11. Shell E. Gauging the Effects of Lead. Scientific American. 2016 Jul; 315(1):23-24. Available from:

http://palgrave.nature.com/scientificamerican/jo urnal/v315/n1/full/scientificamerican071623.html

12. Childhood Lead Poisoning Data, Statistics, and Surveillance [Internet]. Centers for Disease Control and Prevention (CDC); [updated 2016 Sept 01] [cited 2016 Oct 21]. Available from: http://www.cdc.gov/nceh/lead/data/index.htm

13. Hornung RW, Lanphear BP, Dietrich KN. Age of Greatest Susceptibility to Childhood Lead Exposure: A New Statistical Approach. ehp. 2009 Aug; 117(8):1309-1312. Available from:

https://www.ncbi.nlm.nih.gov/pmc/articles/PMC $2721877 /$

14. Massey A, Steele J. Lead in Drinking Water: Sampling in Primary Schools and Preschools in South Central Kansas. J Environ Health. 2012 Mar; 74(7):16-20. Available from: https://www.ncbi.nlm.nih.gov/pubmed/2242831 8 
15. DeNisco A. Lead fears turn spotlight on underfunded facilities [Internet]. District Administration; [updated 2016 Jun] [cited 2016 Oct 21]. Available from: https://www.districtadministration.com/article/le ad-fears-turn-spotlight-underfunded-schoolfacilities

16. Miranda M, Dohyeong K, Hull A, Paul C, Galeano M. Changes in Blood Lead Levels Associated with Use of Chloramines in Water Treatment Systems. ehp. 2007 Feb; 115(2):221225. Available from:

https://www.ncbi.nlm.nih.gov/pmc/articles/PMC 1817676/

17. Coles R, Mishra S, Shashidhara N, Venkatesh T. "Lead Leached into Water from Select Plumbing Fixtures" Could Lead to Health Hazard. Journal Of Krishna Institute Of Medical Sciences University 2014 Jan; 3(1):49-56.

Available from:

https://doaj.org/article/47be7e9aa38f488682269 ed9e663501f

18. Public List of Licensed Child Care Facilities - Fraser North (Health Service Delivery Area \#22) [Internet]. Fraser Health: Community Care Facilities Licensing Program - Health Protection; [updated 2017 Mar 06] [cited 2017 Mar 21]. Available from: http://www.fraserhealth.ca/media/ChildCareFaci lities_NORTH.pdf

19. Public List of Licensed Child Care Facilities - Fraser South (Health Service Delivery Area \#23) [Internet]. Fraser Health: Community Care Facilities Licensing Program - Health Protection; [updated 2017 Mar 06] [cited 2017 Mar 21]. Available from: http://www.fraserhealth.ca/media/ChildCareFaci lities_SOUTH.pdf

20. Public List of Licensed Child Care Facilities - Fraser East (Health Service Delivery Area \#21) [Internet]. Fraser Health: Community Care Facilities Licensing Program - Health Protection; [updated 2017 Mar 06] [cited 2017 Mar 21]. Available from: http://www.fraserhealth.ca/media/ChildCareFaci lities_EAST.pdf
21. Create forms - Collect and organize information big \& small with Google Forms [Internet]. Google; 2017 [cited 2017 Mar 21]. Available from:

https://www.google.ca/forms/about/

22. Office 2010 - Word 2010 [Internet]. Microsoft; 2017 [cited 2017 Mar 21]. Available from: https://products.office.com/enus/microsoft-word-2010

23. Requirement for Informed Consent Document [Internet]. Health Canada; 2014 [cited 2016 Oct 21]. Available from: http://www.hcsc.gc.ca/sr-sr/advice-avis/reb-cer/consent/indexeng.php

24. NCSS 11 Data Analysis [Internet]. NCSS Statistical Software; 2015 [cited 2017 Mar 21]. Available from:

https://www.ncss.com/software/ncss/

25. Statistical analysis and reporting - IBM SPSS Statistics [Internet]. IBM; 2017 [cited 2017 Mar 21]. Available from:

https://www.ibm.com/us-

en/marketplace/statistical-analysis-andreporting?S_PKG $=$ ov $54627 \& \mathrm{~cm}$ mmc $=$ Search Google-_-IBM+Analytics_Data+Science-_WW NA- -

spss_Exact_ov54627\&cm_mmca $1=000000 \mathrm{OA}$

$\& \mathrm{~cm} \_\mathrm{mmca} 2=10000380 \& \mathrm{mkwid}=800 \mathrm{c} 8237$ -

c1a7-49e4-9b98-

9f9cd54cbb97|470|40483\&cvosrc=ppc.google.sp ss\&cvo_campaign $=I B M \% 20$ Analytics_Data $\% 2$ 0Science-

WW_NA\&cvo_crid=163718252630\&Matchtyp $\mathrm{e}=\mathrm{e}$

26. Office 2010 - Excel 2010

[Internet].Microsoft; 2017 [cited 2017 Mar 21]. Available from: https://products.office.com/enus/microsoft-excel-2010

27. Bebek, M. \& Karakilic, V. Assessing Knowledge Differences Between Daycare Staff and Parents: Lead Sources and Health Risks for Children [Internet]. BCIT; 2016 Apr [cited 2017 Mar 21]. Available from: https://circuit.bcit.ca/repository/islandora/object/ repository\%3A325/datastream/PDF/view 
28. Heacock, H. ENVH 8400 Research design \& data collection lecture slides. BCIT: School of Health Sciences; 2016.

29. Loo, M., Heacock, H, \& Afshari, R. Evaluation of the Public's Knowledge, Attitude, and Practice on Seafood Contaminants. BCIT: School of Health Sciences; 2016.

30. Heacock, H. Research Methods Module 5: Inferential Statistics: one-sample t-test, Paired ttest, Two-sample t-test, Chi-square test, ANOVA, Regression \& Correlation. BCIT: School of Health Sciences; 2016.

31. BRITA [Internet]. The Clorox Company of Canada; 2014 [cited 2017 Feb 19]. Available from: https://brita.ca/

32. Coliform Bacteria in Drinking Water Supplies [Internet]. New York State Department of Health; 2011 [cited 2016 Oct 19]. Available from:

https://www.health.ny.gov/environmental/water/ drinking/coliform_bacteria.htm

33. Protecting Children from Lead in Drinking Water at Child Daycare Facilities [Internet]. Vancouver Coastal Health (VCH); [updated 2017 Jan 12] [cited 2017 Mar 12]. Available from: http://www.vch.ca/Documents/Lead-indrinking-water-protecting-children-at-day-carefacilities.pdf
34. NSF/ANSI $42 \& 53$ Drinking Water Treatment Units [Internet]. National Sanitation Foundation (NSF); 2017 [cited 2017 Feb 19]. Available from: http://info.nsf.org/Certified/dwtu/listings.asp?Co mpanyName $=$ brita\&submit $1=$ Search + by + Manuf acturer\&Program=DWTU

35. Certified Drinking Water Treatment Units: NSF/ANSI 42 [Internet]. Water Quality Association (WQA); 2017 [cited 2017 Feb 19]. Available from: https://www.wqa.org/findproducts/ctl $/$ detail $/ \mathrm{mid} / 1054 / \mathrm{cid} /$ brita_lp/sid/1/ke yword/brita

36. Certified Drinking Water Treatment Units: NSF/ANSI 53 [Internet]. Water Quality Association (WQA); 2017 [cited 2017 Feb 19]. Available from: https://www.wqa.org/FindProducts/ctl/Detail/mid/1054/cid/BRITA_LP/sid 13

37. Brita ${ }^{\circledR}$ Water Filtration Process [Internet]. The Clorox Company of Canada (CCC); 2014 [cited 2017 Feb 19] Available from: https://brita.ca/water-filtration-process/

38. Frequently Asked Questions [Internet]. The Clorox Company of Canada (CCC); 2014 [cited 2017 Feb 19]. Available from: https://brita.ca/water-filtration-process/waterquality-contamination/ 